\title{
Striving for being in the line of life: Personal Active Ageing Strategies among Iranian
} elder

Fatemeh Raeesi Dehkordi', Ahmad Ali Eslami*1, Fereshteh Zamani Alavijeh'. Hossein Matlabi $^{2}$

1. Department of Health Education and Promotion, Isfahan University of Medical Sciences, Isfahan, Iran.

2. Department of Health Education \& Promotion, Tabriz University of Medical Sciences, Tabriz, Iran.

Corresponding Author: Professor, Head of Department of Health Education and Promotion, School of Health, Isfahan University of Medical Sciences, Isfahan, Iran,

Mobile: 09124214268, Tel: 03137923242 ,Fax: 03136682509,

Email: 1 (Eslami@HLTH.mui.ac.ir, 2) eslamiaa@gmail.com 
Striving for being in the line of life: Personal Active Ageing Strategies among Iranian elder

\section{Abstract \\ Background:}

Active ageing is a multidimensional, relative, and context-dependent concept with different paths and outcomes. The purpose of this qualitative study was to explore personal active ageing strategies in a specific context.

\section{Method:}

Following a directed content analyze procedure, we conduct semi structured individual interview with 39 elder (men and women) between the ages of 60-97 years that selected with purposeful sampling .data collection and analysis were concurrent. We analyzed the data from interviews, written narratives, and field notes using directed content analyze. The Reliability of data was fulfilled in accordance Lincoln and Guba criteria. We stopped data collection when no new concept was added and data saturation occurred. 


\section{Results:}

Based on the experience of elders, we identified 5 categories: 1) Preventive 2) Coping 3) Internal self-control 4) Coherence maintenance strategies 5) Opportunity exploiting strategies. These described the active ageing strategies when encountering with age related change. Utilizing these strategies, the elder accompanied the life time.

\section{Conclusion:}

The finding suggests that active ageing is a continuous process in confronting age related change. The identified strategies can help to promote active ageing by familiarizing older with opportunities of life and training them in how to use these strategies.

Key words: Iran, active ageing, elderly, qualitative study

\section{Introduction}

Aging is not only a population phenomenon but also an individual experience (FernándezBallesteros, Robine, Walker, \& Kalache, 2013) with biological, cultural, psychological and spiritual dimensions(Cunti \& Bellantonio, 2018). In addition to age and gene, the interaction of environmental and social conditions, as well as individual and behavioral factors affects aging. It is not a random phenomenon(Fernández-Ballesteros et al., 2013).

According to a prediction of the World Health Organization, old men and women can expect to live an average of 0.9 and 0.8 years per decade longer respectively; this indicates the growth of the ageing population in recent years. However, in the past, ageing was regarded as a stage of dependence, being a burden, wasting time and waiting for death. But in the 21st century paradigm, a shift in the conceptualization of ageing occurred which introduced ageing as a purposeful stage with an opportunity for maturity and development. Accordingly, older adults are regarded as treasures considering their experiences and knowledge (despite losing their physical capabilities) (Buys \& Miller, 2006).

A key question in countries with a growing population of older adults is how some older people, unlike their peers, continue their daily activities. How does an older adult live 
independently and manage his/her life while a younger one is not even capable of taking care of his/her own personal life. (Marcum, 2013).

To answer this question, in recent years, new concepts with a common message have emerged and provided a positive perspective of aging. Among these concepts, active aging is a more comprehensive (Walker, 2002), multi-dimensional and relative concept encompassing the concepts of productive aging (social payment and welfare state) and healthy aging (staying healthy in the final years of life by practicing healthy habits) (Katz, 2013). Active aging entails continued participation in social, cultural, religious and economic contexts. This term based on social gerontology and Activity Theory. (Victor, 2004).

Various definitions for active ageing have been offered so far. D 'Souza has defined active ageing as senior's efforts to control potential resources for themselves as well as their society's development (Moulaert \& Paris, 2013). Moreover, Kalache(1999)has defined active aging as the process of optimizing opportunities for physical, mental and social well-being throughout the course of life to promote a healthy life span expectancy(Del Barrio, Marsillas, Buffel, Smetcoren, \& Sancho, 2018).

In addition to emphasizing the importance of cultural context and the norms related to where a person lives, the World Health Organization (2002) expanded on earlier definitions and defined active aging as the process of optimizing opportunities for health, participation and security (based on a life-long approach)(Organization, 2002). Active aging puts more emphasis on social aging (years of life) rather than population aging (Zaidi \& Howse, 2017) and seeks to promote the concept of "adding life to years". This enables people to not only remain functional and active for a greater number of years, if needed, but also to be more productive and healthier in retirement (Walker, 2002). Active aging leads strategic programs from a needs-based approach (an older adult is considered inactive) toward a rights-based approach(Cox \& Pardasani, 2017).Concept of active aging is still vague since the meaning of the term active varies in different societies and most of the existing models have been developed based on a western perspective(Thanakwang, Isaramalai, \& Hattakit, 2014). Active aging is characterized within a biomedical range of an extended life span, physical health(Hirai, Kondo, \& Kawachi, 2012; van Dyk \& Turner, 2010), lack of dependence(Jumadi et al., 2019), social participation(Formosa, 2019b), maintaining cognitive functions and stress management (Fernández-Ballesteros, Molina, Schettini, \& Del Rey, 2012), care of grandchildren, preparedness for death (Nantsupawat, Kamnuansilapa, Sritanyarat, \& Wongthanawasu, 2010), participation in the labor force(Foster, 2018), life satisfaction (Wu et al., 2018) also life-long 
learning(Costa, Veloso, Loizou, \& Arnab, 2018). Hence, studies have repeatedly reported the need for a scientific definition of active ageing as well as a culture-based model (UdO, 2016). Based on the 2016 demographic census's results aged people constituted about $9.3 \%$ of the country's population and the majority of whom were women. Only $46 \%$ were literate, $27 \%$ lived without their spouses (46\% of women and $9 \%$ of men) and one-fourth were employed (Afshar, Asgari, Shiri, \& Bahramnezhad, 2016).

Most Iranian seniors were not financially independent enough to improve their lifestyles. Although the age structure of Iran's population is not an aging one, it is predicted that by the year 2050, about a quarter of Iran's population will be the elderly(Mehri, Messkoub, \& Kunkel, 2019) and bearing the highest burden of chronic diseases such as cancer and cardiovascular diseases. This will impose many negative burdens on the health care system(Asrani et al., 2018). Iran's cultural context differs from other countries and the majority of its people are Muslims(Ahmadi et al., 2018). Islam and the Iranian culture honor the elderly. A review of ancient Persian literature reveals the great respect for elders in the Iranian culture(Heravi-Karimooi, Anoosheh, Foroughan, Sheykhi, \& Hajizadeh, 2010).

Being active in the Islamic-Iranian culture is different from that western societies and is associated with religious beliefs. Although Health Promotion Program has been considered in recent years(Hassani, Izadi-Avanji, Rakhshan, \& Majd, 2017) But, there is no center for active aging in Iran. The researcher believes that the needs and concerns of Iranian elderly for active aging are unknown and western models cannot explain active aging strategies in Iranian older adults(Speziale, Streubert, \& Carpenter, 2011). On the other hand, active aging is a subjective and depends on the presuppositions and inner experiences of individuals (Mohammadi, Allahyari, Darvishpoor Kakhaki, \& Saraei, 2018). Seniors tend to live independently and protect their privacy with or without minimum intervention from others (Illario et al., 2016) Various studies emphasized that personal independence, management of life and participation in society (Rantanen et al., 2018). Furthermore, no quantitative approach can explain active ageing strategies. We have thus undertaken as deep and comprehensive a study of this phenomenon as possible via qualitative approaches. This study is part of a larger study that describes the concept of active aging among Iranian seniors using a directed content analysis procedure. One of the main categories was striving for being in the line of life: describes the personal active aging strategies of Iranian elders.

\section{Materials and Methods}

This qualitative study addressed the following questions: what does the lived experience of active ageing strategies from the perspective of an older adult? 
This study conducted between February 2018 and March 2019. The main participants were the community -dwelling elderly over age 60 living in Isfahan (third largest city in Iran) choose people over 60 was based on Brunner and Suddarth's classification criteria, the UN criteria, and the fact that aging in Iran begins 5 years earlier compared with advanced countries. The participant who had been through the experience of aging, were invited to participate. These participants were selected purposively from three aging groups (young-old, old, and oldold) (Kowal \& Dowd, 2001). After purposive sampling, we collected data from people who could provide the appropriate and relevant data for completion concepts, categories.Based on the principle of maximum variation in sampling (Bonsu, Dhubháin, \& O'Connor, 2019) participants came from a heterogeneous perspective and experiences (occupations, marital statuses and number of children). Elderly were recruited from different setting: retirement home, physicians' offices, city parks, elderly people's workplaces, health centers and mosques. We arranged the interviews according to participant preferences: their homes, parks, mosques, etc. Snowball sampling (introduced by previous participants) was used to recruit some participants. This technique does not contradict purposeful sampling(Lune \& Berg, 2016).

. In total, 39 participants, aged of 60-97 years, who volunteered, consented and had inclusion criteria participate in the study: 1) able to speak Farsi, 2) Good cognitive function

and obtaining a score of 7 or higher on the Persian version of the Abbreviated Mental Test (AMT) (Bastani \& Beigi Boroujeni, 2019; Piotrowicz et al., 2019), 3- completing an written informed consent form including audio taping and transcription of the interview. No identifying information was included in the analysis or presentation of the findings. Signed consent forms were kept separately from the audio files and transcripts to ensure confidentiality was maintained at all times. Audio recordings were destroyed prior to April 1, 2019.

We conducted interview in Persian, face-to-face, semi-structured with open ended question based guide. A total of 39 interviews were conducted.

During each interview, we started with general and primary questions including: Please tell me about your life? Tell me about your one day/week? What comes to mind when you hear active aging? According to the responses, the interview guide was amended for clarification to the questions. "What do you do to be active?' During the interview, we asked additional questions, when needed, for exploring the ideas expressed by the participants. Open-ended questions created by the researcher, based on the literature, and in consultation with professionals who work with older adults, targeted active aging. 
Interview lasted an average 85 minutes in length (30 to 140 minutes) according to the participant's willingness and ended when participants became fatigued. We audiotaped interviews and subsequently transcribed them verbatim. The Interviews were recorded using a Lander LD-71F voice recorder. In one case, due to the participant dissatisfaction, the reminder keywords were written down by the researcher during the interview, and the text was immediately returned to the participant after which it would be transcribed. Written field note and memos were included in the analysis (Mihas, 2019) Data collection and directed content analysis procedures(Pandey, 2019) were concurrent to identify new and emerging themes.After listening to the audio files several times, initially, each interview was transcribed using Word 2013. The analysis process was a line by line reading of the transcript and identification of the significant phrases and words (open coding, was identified through line-breaking) which were extracted using the New Comment. The initial codes were categorized based on continuous comparison of similarities and differences in various parts of the data. Special questions would be written in the left column of the sheet if a part of the interview was ambiguous and the participant was asked these questions. We conducted focus and axial coding and discussed emerging themes, concepts during the meeting.

After coding and analysis for the final two interviews, all data were replicated until no new categories or concepts were added. In addition, the concepts were formed. Therefore, we stopped data collection due to theoretical saturation.We ensured trustworthiness of the study through various method(Larsson, Hildingsson, Ternström, Rubertsson, \& Karlström, 2019). Prior to the qualitative interviews, sessions were held for familiarity with the participants. For enhancing conformability and dependability of findings, from participants and three external qualitative researcher were asked to checked participant experiences and findings.Member checking prolonged engagement in the study while maximum variation in sampling established credibility .Finally, we clearly described participants' characteristics, study process, sampling, as well as location and research limitations to enhance transformability of data. The Research Ethics Committee of Isfahan University of Medical Sciences approved the study (no. 395911) and the participants were assured of the confidentiality in this study.

\section{Results:}

In all, there were 39 participants, aged 60-97 years with a mean of 74.28 years who volunteered and consented to participate in the study (Table 1).

Table 1: socio- demographic characteristic of participants 


\section{Number $($ Total $=39)$}

\begin{tabular}{|c|c|}
\hline Age & \\
\hline Young old $(60-74)$ & 10 \\
\hline$(75-89)$ & 16 \\
\hline (over 90) & 13 \\
\hline Education & \\
\hline Illiterate & 11 \\
\hline Literate (reading and writing ) & 6 \\
\hline Elementary school & 7 \\
\hline Middle school & 6 \\
\hline Diploma & 6 \\
\hline Bachelor's degree & 2 \\
\hline Illiterate & 1 \\
\hline Marital status & \\
\hline Married & 17 \\
\hline Widowed & 11 \\
\hline Divorced & 3 \\
\hline Single & 8 \\
\hline Living with whom & \\
\hline Living independently & 5 \\
\hline Living with spouse & 7 \\
\hline Living with son and family & 5 \\
\hline Living with unmarried child & 6 \\
\hline Living with caregiver & 2 \\
\hline Living with an older -relative & 3 \\
\hline Employment Status & \\
\hline Housewife & 16 \\
\hline Retired & 9 \\
\hline Employed & 8 \\
\hline Retired(Returning to work ) & 6 \\
\hline
\end{tabular}

Five categories emerged from data that described active aging strategies: 1) Preventative 2) Coping 3) Internal self-control 4) Coherence maintenance and 5) Opportunity exploiting 
strategies. In fact when encountering age- related changes participants would prevent a threat before its occurrence. In cases where the counteraction failed, they used internal self -control strategies to maintain their internal and external cohesion dealing with life. They optimize the passage of time to pursue their own interests (Diagram1).

\section{1-Preventive strategies}

The elderly encountered various changes during ageing that they either experienced personally or observed in others. They prevented possible future threats. Anyway, they adopted preventative health promoting behaviors, seeking family and social support.

\section{1-1 Health Promoting Behaviors}

The seniors encountered changes in the physical, cognitive, social dimensions during the process of aging. By adopting a healthy lifestyle, caring for their health. . In this way, they were safeguarded against possible physical, cognitive, and psychological threats they were prone to.Physical activities pattern, having healthy eating habits, avoiding tobacco and addictive substance use, and having healthy sleep delayed negative changes in the process of ageing

\section{1-1-1 Physical Activity pattern}

Some seniors believed that physical activity would make them feel healthy as well as curb negative emotions. Younger seniors would prefer traveling and exercising, but, stay-at-home seniors preferred to solve crossword puzzles. Some seniors believed that walking was not enough physical activity.

"I use park fitness equipment in the morning, and sometimes one of my friends stands in the middle and we stand around him as a means of support”. (An 81-year-old man)

\section{1-1-2 Healthy Eating Habits}

The older adults all believed that healthy eating habits should be adhered to in order to maintain their health:

"From the beginning of my life, I've always been careful not to eat too much. When you get old, you can't eat everything because you get sick easily.". (An 68-year-old woman)

Of course, their eating habits depended on the economic status of their family and the expectations of others. "I eat chicken rather than red meat, though it can cause harm. I've heard fish is good but it is too expensive for me to afford". (An 76-year-old man).

\subsubsection{Avoiding tobacco and addictive substances use}


Some older adults had used addictive substances and tobacco to relieve chronic pain and illness; however, they encountered an increase in physical and mental issues resulting in social stigma from family and society:

"I remember my dad used to smoke opium when I was a child until I grew up and wanted to see what he was smoking. Everybody had rejected him. One day my dad fell dead beside his brazier and since then I've been scared'. (An 60-year-old man)

\section{1-1-4 healthy sleep}

Abnormal sleep patterns interfere with mental and emotional functioning: ""Whenever I don't sleep well at night, I feel too tired the next day”. (An 70-year-old man).

\subsection{Seeking family and social support}

Family and social support is one of the factors that affect life satisfaction through creating positive emotions and perceptions. Seeking family and social support are described in this subcategory.

1.2.1. Seeking Family Support including emotional, informational and instrumental support from the children and relatives. Even the elderly who lived alone sought to attract their support to prevent the occurrence of negative thoughts and unpleasant emotions. "Whenever I feel anxious I'll call my daughter, she'll come and insist on staying with me”. (An 71-year-old man)

1.2.2. Getting social support: In addition to family support, the participants believing that governmental financial support (insurance, charity organization and dignity card for the elderly) will be useful for them. Health insurance is so limited in Iran. Most of the medical expenses will be borne by the elderly or their families

"It's important to support the elderly, especially those who live alone and don't have anybody. The government should set up clubs for them. We aren't supported at all. If I didn't receive a salary now, who would support me? There's a lady in our neighborhood that can't go down the stairs, a trained assistant should help her". (An A 61-year-old man)

Of course, the quality of support was more important than its quantity (number of individuals in the social network). Some participants complained about a lack of emotional and social support: "I'd like my daughter to bring me a pot of food or at least come and ask me what I need done? What a pity”! (An 77-year-old woman)

\section{2- Coping strategies}

When faced with threat, the elderly tried to actively control their behavior or situation. Ceasing or modifying previous behaviors, adjusting living environment, using 
assistive devices for age related deterioration were strategies used by the seniors to cope with threats so that they remain in life-time passing. The seniors used one or more strategies when faced with the threats of aging.

\subsection{Ceasing or modifying previous behaviors}

When faced with change the elderly stopped or modified their behavior to prevent the threat from manifesting itself. This approach could be temporary or permanent and helped the elderly maintain their physical and mental health: "I used to walk to my relative's home but I can't walk much anymore. I can no longer stand up in the kitchen and do my work. I have to sit down on a chair to ease my pain. Whenever I get sick, I rest, I can't work when I am sick”. (An 88-year-old woman)

\subsection{Adjusting living environment}

Based on changes in the ageing experience, the elderly regulated their living environment. This included changes in their environment, making changes at home (getting rid of excess furniture) placing personal items for easier access: "Our previous house was very big and old. I'd told my spouse I couldn't clean the house anymore as I was suffering from back pain. We sold that house and bought a smaller one”. (An 79-year-old woman) 


\subsection{Using assistive devices}

The elderly used walkers, eyeglasses and crutches to correct degenerations faced over the passing of time, maintain their independence and experience active ageing: a participant was trying to walk to the kitchen with walkers to warm his food. (An 95-year-old woman).

\section{3-Internal self-control strategies}

This strategies helped elderly to be accompanied with changes in life time passing. This strategy used along with other strategies or alone to accompany the passing of life, especially when other strategies were not effective. Feeling hopeful about the future, creating happiness, appeal to spirituality and transcendence described this sub category.

\subsection{Feeling hopeful about the future}

Hope was an effective mental strategy in the elderly to deal with the threats. "Well, illnesses occur as we get older. I won't be demoralized. I won't accept disappointment. A life without hope will make you sick and the darkness of life will overtake you. Life can be wonderful if you have hope". (An 83-year-old man)

\section{3-2 Creating happiness}

Happiness was found to be helpful for mood control in older faced with the threats of aging.

. "I don't attend mourning ceremonies. I'm looking for the programs that make me happy" (An 81 year-old-woman).

\subsection{Appeal to spirituality and transcendence}

Reliance on a superior power (God) enhances ones' mental capacity, especially in the context of the Iranian society. It is used to deal with age related change throughout life. Belief in the divine fate, thanksgiving, and religious behavior and worship categorized under spirituality. Self-transcendence, accepting the mysteries of life, and positive solitude described the transcendence subcategory.

\section{3-5-1 Appeal to spirituality}

\subsubsection{Belief in divine fate}

Reliance on God and the Imams would help the elderly to overcome threats, pay attention to their afterlife and trigger spiritual activities including helping poor people

\subsubsection{Thanksgiving}

Thanksgiving would keep all of their attention focused on the present moment rather than on the past or future. This would allow them to assess their lives as more useful and positive.

"Every night I go into the yard, look up at the sky and say : thank you my Lord, for all you've given, for all you haven't given and for all you've taken. Whatever you've given is your 
blessing, whatever you haven't given is due to your wisdom and whatever you've taken is a test". (An 85-year-old man)

\subsubsection{Religious behavior and worship}

The elderly frequently used these strategies: religious practices, prayers, attending mosques and religious sessions as well as reciting certain verses of the Holy Qur'an. These strategies would discharge negative emotions: "I start my days relying on God; I send blessings upon the prophet and his family. I may forget some things but I always repeat the last verse of Surah Baqarah which God advised the Prophet to recite in order not to ever forget anything ". (A 65year-old woman).

\subsubsection{Transcendence}

Transcendence comprises Self-transcendence, belonging to a country, accepting the mysteries of life, and positive solitude.

\subsubsection{Self-transcendence}

Many respondents expressed a state of constant change and development: "Although I can't walk, I am a benefactor. Money doesn't matter. I consider others more than myself. The only thing that makes me happy is to feel like I do have an impact in people's lives". (An 70year-old man)

\subsubsection{Accepting the mysteries of life}

Some of the elderly look at the world from a higher perspective and accept the mysterious aspects of life, rather than finding a reason for each phenomenon: "I used to be an analyst who thought that everything happens for a reason. But I ruined my life. Now I think I should enjoy the beauty of life". (An 79-year-old man) 


\subsubsection{Positive solitude}

: Most participants enjoyed loneliness, became more selective in their choice of companions, preferred to spend time with people they already knew, instead of making new friends. "I'd like to put everything aside and enjoy solitude. The number of my friends hasn't changed but my form of communication has changed: "I used to get together with my friends and talk nonsense. Without solitude life is meaningless and superficial”. (An 89-year-old man)

\section{Coherence maintenance strategies}

- Adjustment to change, acceptance of death as well as positive self-image were the theme of the internal coherence subcategory while physical appearance and adornment indicates external coherence.

\section{4-1. Internal Coherence}

\subsubsection{Adjustment to change}

Ageing is accompanied by many changes such as: changes in living arrangements (smaller families), work pattern. Adjustment helped individual to maintenance of his/her individual independence and providing compatible interaction with others. Some older adults could adapt to these changes, but others couldn't. "I get scared when I think about old age. I'll kill myself if I become bedridden when I get old. I can't come to terms with it at all”. (An 57-year-old woman)

\subsubsection{Acceptance of death}

The study findings showed that the participants who believed the mystery of life were not fearful of death's pain and experienced less anxiety at the thought of it. An elderly person with a physical disability said, "Now that death is close, I'm not afraid, dying isn't difficult, it is a rebirth. Death means God" (An 84-year-old woman) 


\subsubsection{Positive self-image}

Senses of usefulness and ability in the aged which appeared when there was no change in one's life course despite losses caused by the passage of time. Older adults with higher selfefficacy felt better about themselves. In contrast, some of them felt incompetent and useless in society. "I feel sloppy, ugly and lost. I'm a dead loss. I have no physical ability and feel like I can't do anything”. (A70-year-old woman)

\section{4-2 Physical appearance and adornment}

Being clean and tidy in appearance prevents depression and isolation and is effective in accepting the elderly into their family and society. "I don't understand why some old people think they don't have to be clean and tidy in appearance when they get old. They always wear dark clothes. You don't need really expensive or new clothes but you need tidy ones. No one likes to talk to untidy old people who don't care for themselves". (An 83-year-old man).

\section{Opportunity exploiting strategies}

Along with preventive or internal self- control strategies, the elderly tried to pay attention to new life opportunities. Some of the participants considered ageing as an opportunity rather than a period of inactivity. Active intuition, learning activities and the creation of artwork described this subcategory.

\section{5-1 Active intuition}

Some participants were purposeful in their lives. Purpose and Planning, knowledge development are in this subcategory.

\section{5-1-1 Purpose and Planning}

Some of the participants would not waste their time after retirement. They would plan to perform different roles throughout their life course. "I think about the things I want to do and where I want to go throughout the day when I wake up in the morning. I classify them. I'll do it even if it's hard for me”. (An 80-year-old man) 


\section{5-1-2 Knowledge Development}

The Participants searched through books and social network for health information: "I have a laptop and can search. Whenever my doctor prescribes a medicine or test I'll search on the Internet. Or I'll ask others in the park. I'll ask about everything: economics, social issues, and even health issues. Sometimes I read a newspaper". (An 75-year-old man)

\subsection{Learning Activities}

In addition to improving previous skills, the participants learned and taught new skills and modern technologies in order to keep themselves active.

\section{5-2-1 Improving previous skills}

Some participants pursued their previous interests and skills, which they had previously abandoned because of their busy life: "I was taking care of my husband until he died. I have more free time now. I can go to art classes just like I enjoyed doing when I was young ". (A 62year-old woman)

\subsubsection{Learning new skills}

Some participants believed that aging is not a time for isolation and their experience gained during life helped individuals optimize remaining lifetime : "I have free time now, I'd like to go to English classes and take coaching swimming courses, these activities make me feel young." (An74-year-old man)

\subsubsection{Learning modern technology}

Modern technology was a strategy used for talking to their relatives, grandchildren and for consulting. Of course many of them were unable to align themselves with the requirements of modern life.

Lack of knowledge and skills for using modern technology was a threat to their independence. "I've been living in Isfahan for 50 years. I don't know how to use an ATM and withdraw my pension. I have no body to help me with my work. Once I gave my card to somebody and asked her to withdraw my pension for me. She withdrew a lot of money from my bank account for herself. It bothered me". (An 81-year-old woman) 


\subsection{Creating Artworks}

This strategy helped the older people improve their abilities and reduce stress. It included creation of visual graphic arts and literature (story and poetry), participation in theater performance and playing music . Some of the elderly had even won prizes or earned income by selling their work. "I don't waste my time sitting idle and waiting to die. I write poems and stories. One of my books which is the story of my life and memories was published. I've already sold some copies”. (An 84-year-old woman)

"I was an instructor and a theatre director at the Armenian Church in Esfahan. I have managed a lot of plays and been awarded a UNESCO prize ". (An 77-year-old man)

\section{Discussion}

The elderly are subjected positive or negative changes throughout their life. The present study showed that older Iranian adults use interactive strategies to deal with emerging threats and pay attention new opportunities to age actively. In fact "It's not important that we get old, our behaviors throughout our lifespan matter" (del Pilar Díaz-López, López-Liria, AguilarParra, \& Padilla-Góngora, 2016). According to Kahana and Kahana model, preventive strategies are applied to reduce threats, to avoid negative consequences and control change (Kahana \& Kahana, 2001). It is consistent with the preventive strategies of the SOC model that seek to acquire resources for achieving life goals(Sottimano, Guidetti, Viotti, \& Converso, 2019). These behaviors represent conscious selection and are influenced by social factors (Brojeni, Ilali, Taraghi, \& Mousavinasab, 2019; Monfared et al., 2019). Preventive behaviors in older adults differ from youth (Chung \& Park, 2019) and have an important role in longevity and quality of life (Seib et al., 2019). The participants, especially those who were not old, prevented the occurrence of health threats through health promoting behaviors (healthy eating habits, sleep patterns and physical activity). This was consistent with the findings of the Lachman(Lachman, 2006) and Flood model(Flood \& Phillips, 2007; Liotta et al., 2018). Physical activity was one of the important strategies used by the elderly in the present study that was considered in developed (Landi et al., 2018) and developing countries (Nantsupawat et al., 2010) under the title of "physical activity and healthy lifestyle". Physical activity intervention in the elderly prevented cognitive decline (Zhao et al., 2018) and depressive symptoms (Mašanović, Popović, Bjelica, Vukotic, \& Zoric, 2018).

On the other hand, sleep is one of the basic human needs (Ding, Jiang, \& Riloff, 2018) and health promoting behaviors(Lentz \& Brown, 2019). The prevalence of sleep disorders in elderly have been reported at 6-62\% (Gulia \& Kumar, 2018). Quality and pattern of sleep change with aging, caused to impaired cardiovascular function(St-Onge, Crawford, \& 
Aggarwal, 2018), increased risk of falls and dementia(Morelhão, Pinto, Gobbi, Tufik, \& Andersen, 2018; Shi et al., 2018). Health promoting behaviors are affected by the culture and religion of the society(Dickerson et al., 2018). For example, in Thai people, Buddhism has an indirect impact on health (Winzer \& Gray, 2019). In Iranian culture health promoting behaviors are affected by social support (Alizadeh, Keshavarz, Mirghafourvand, \& Zayeri, 2018) . The findings of this study showed that responsibility and negativism affect health promoting behaviors. Negativism caused older adults to think that change is unmanageable and any attempt to control (Shackman et al., 2016). In some studies, social support has been considered as one of the dimensions or strategies of successful aging that provides life opportunities and facilitates for active aging strategies (Pashaki, Mohammadi, Jafaraghaee, \& Mehrdad, 2015). Justified by Iranian culture, family is a cohesion network, was more important than western countries so that having no children or being single could affect their life .Our participants viewed their children as the fruits of their life and those who had no children had to employ a caregiver. In fact, active aging in Iran occurred in a setting where unsupportive context affected the psychological health. On the other hand, Iran's economy relies on the government which is responsible for supporting citizens economically as well as providing welfare for them (Farzanegan \& Alaedini, 2016).In this study, lack of pay for housewives, lack of income security and low pensions affected the quality of life of the elderly. According to other studies, perceived social support was more important than received support (Eagle, Hybels, \& Proeschold-Bell, 2019).

When faced with change over time, coping strategies are used. According to activity theory, active aging encompasses replacing the lost roles and age- related losses and changes to maintain a positive sense of self (Principi et al., 2018). SOC model recommended replacing achievable goals (Boucher \& Dahlke, 2019). In fact, when goal-related tools are no longer available, re-selection of goals and optimization strategies are used to compensate declines. The elderly people compensated via using technologies such as hearing aids, wheelchairs and eyeglasses (Schilling et al., 2012). This indicates the need for more effective community-based rehabilitation. Of course, our country faces limitations in this regard (insurance coverage and production of rehabilitation equipment)(Mousavi et al., 2019).

In the present study, involvement with age-related changes and their psychological consequence provided the context for using internal self -control strategies including spending time, feeling hopeful, joy of creativity and appealing to spirituality and transcendence. This strategy was used in the elderly who had experienced many threats over time and when other strategies were not effective. In fact, these mechanisms were a kind of psychological control 
when facing external demands and the basis of success in the modern world (DeLisi, 2014; Finley \& Schmeichel, 2019).Our participant optimizes their lives by distraction negative thoughts via engaging in pleasant activities. Based on activation theory of emotion, one's perception of the future has a great impact on his/her selected goals. The older adults who perceived future as precious adopted a more proactive and positive approach by being active (Luth, 2016).feeling hopeful will lead to the acceptance of age-related changes and could help the elderly to predict the outcomes of their behavior and have expectations for the future and accepting their individual and social roles(C.-S. Lee, Ryu, \& Choi, 2019; Zhang, 2012) .Joy contributed to maintain autonomy in daily and social activities(Tastan, Ayhan, Kose, Iyigun, \& Gokcul, 2019) healthy aging(Pichler et al., 2019), satisfaction with life (Hsu \& Chang, 2015). Recent research has shown that when people get old, they become happier despite the decline in some functional (physical and cognitive) capacities (E. Lee, 2018). Of course, some studies have reported an increase in negativism in older adults(Luchesi et al., 2018) or an inverted Ushaped pattern(Lobos, Lapo, \& Schnettler, 2016).Furthermore, The results of our study are in accordance with studies that referred to the strategies used in the elderly: patience(Hassani, Izadi-Avanji, Rakhshan, \& Majd, 2017), positive thinking(Blevins \& Troutman, 2011), religious orientation(Naik, Reddy, \& Kanungo, 2019), active engagement(Liu, Rozelle, Xu, Yu, \& Zhou, 2019) and avoidance(Bagheri-Nesami, Rafii, \& H. Oskouie, 2010).

Aging is a natural process accompanied by a change in worldview. In the present study, the elderly continue a life path by appeal to spirituality and transcendence. Spirituality flowed throughout life and then strengthened in aging(Lucchetti, Vitorino, Nasri, \& Lucchetti, 2019). Based on the religious context of the Iranian society, spirituality was the most valuable strategy for active aging, used by women more than men. Spiritual beliefs and activities are proactive adaptive behaviors which optimize life's passage in the active aging process and supply provisions for the Hereafter(Ajam Zibad, Mohammadi Shahboulaghi, Foroughan, Rafiey, \& Rassouli, 2016). Transcendence entails a positive view about aging and beyond positivism materialistic perspective. Tornstam believes that the elderly have a chance to grow and achieve wisdom. Wisdom can result in an understanding of the meaning and goals of their lives(George \& Dixon, 2018).In the present study, the participants considered altruistic activity (without expecting compensation) as an innate human attribute which inspired them to be active. Forgiveness might reduce stress and anxiety and lead to psychological wellbeing(Chen, Harris, Worthington Jr, \& Vander Weele, 2019; Rasmussen, Stackhouse, Boon, Comstock, \& Ross, 2019).from the age of sixty, feelings of coherence are in opposition to disappointment (Miao, Wu, \& Sun, 2019). In the face of death, will pose this question in their minds“" Why 
should I live longer"? analyzed their lives in order to achieve a self-concept (Butler, 1963). The study of aging models and theories reveals that older adults experience active aging as long as they have a positive self-perception(Mendoza-Ruvalcaba \& Fernández-Ballesteros, 2016). Boudini points to three key principles of active aging including: Fostering adaptability, supporting emotionally close relationships and removing structural barriers related to age or dependency(Boudiny \& Mortelmans, 2011). Flood's theory also emphasizes adaptation to negative change(Blevins \& Troutman, 2011).

In the present study, some older adults considered themselves active although experienced many adverse events. It seems that major negative changes occurring during youth or childhood can affect one's adaptation especially in old age (Walkner \& Rueter, 2014).

In the present study, maintenance of physical appearance and adornment despite multiple changes was indicative of remaining a life-time. Younger women were worried about appearance changes and tried to maintain their physical appearance despite ageing. But the elderly had accepted their physical appearance and tried to maintain their integrity by an adherence to personal hygiene. In some societies, physical appearance is considered a value and any age-related change is a pathological factor which threatens physical appearance and needs correction. Therefore, the use of cosmetics to cover skin changes increases with age.

Although planning for the future decreases with increase of age, the elderly benefit from it(Ouwehand, de Ridder, \& Bensing, 2007; Wakasai, Matsumoto, \& Kakehashi, 2006).

This enables the elderly to have a more productive life and engage in the activities of family, friends, community and thereby remain independent. In the past years, a majority of Iranian adults had encountered with limited educational facilities; however, learning art skills has been necessary for women. They tried to be useful to others by utilizing their individual capabilities. The feeling of being useful is very effective in volunteering (Pierpaoli \& Parmelee, 2017). On the other hand, they made their lives enjoyable by doing activities and optimized life's passage. This strategy was not clearly observed in other studies. On the other hand formal activities are not suitable for everyone. The elderly, preferred to pursue active subjective strategies rather than being isolated at home. Lifelong learning and acquiring an active intuition indicate an ongoing social participation(Narushima, Liu, \& Diestelkamp, 2018). Engaging in creative activities relieves anxiety and depression(Fancourt, Garnett, Spiro, West, \& Müllensiefen, 2019). Active learning, maintenance healthy life style has been mentioned in numerous studies (Desjardins, Olsen, \& Midtsundstad, 2019; Ferreira, Maciel, Silva, Santos, \& Moreira, 2010; Thanakwang et al., 2014). Not staying at home and 
management home time emerged in this study and social participation has a different meaning in research (Pavelek, 2012; Robertson, 2013).

In developed countries, to promote active aging, The U3A implemented national plans to support and develop lifelong learning programs for the elderly(Formosa, 2019a).In Iran U3A was first launched in April 2012, The duration of the courses are planned as one month terms. Participants need to be 55 years and older and have a high school diploma. They receive a "graduation certificate" at the end of the course (The University of the Third Age in Iran, 2017). In some societies, active aging is equivalent to aging security management (Chan \& Liang, 2013) or preparation for death (Thanakwang et al., 2014) . This illustrates the effect of negative stereotypes in the perception of the elderly. Moreover, new technology offers opportunities for improving memory, cognition and compensating for age-related losses(Anmarkrud, Andresen, \& Bråten, 2019).Some countries, such as Japan, have attempted to develop "on-site aging"(Lai, 2008), and bring technology into homes so that the elderly can experience positive aging at home as well as maintain their personal independence. But the findings of this study and other studies indicated that the elderly do not have enough awareness about new technology(Mitzner et al., 2010; Walker \& Zaidi, 2019). About half of European seniors used the Internet only once a week .In Portugal, the majority of the elderly had never used a computer, or a tablet(Davies, 2011).

Finally, according to the World Health Organization, active aging experience and strategies varies across different cultural contexts (Fernandez-Ballesteros, Olmos, Santacreu, Bustillos, \& Molina, 2017). Preventive strategies reduced the need for coping strategies by reducing the experienced threats. In addition to preventing the occurrence of subsequent threats, coping strategies enabled active dealing with threats and reduced the need for selfcontrol strategies, optimized life passage by using opportunity exploiting strategies. Therefore personal active aging strategies should be promoted(Walker, 2019). 


\section{Conclusion}

There is limited literature on active ageing, Contrary to successful ageing. The strategies introduced in the present study encompass all the criteria and strategies presented in the other studies. In our study, active ageing was a dynamic process attained through preventative, coping, and other strategies. These strategies have been used together or sequentially to help the elderly deal with life. Based on available statistics, one-tenth of the current population of Iran and one-fourth of its future (next 35 years) population are old. A lot of attention has been paid to this group in health development programs in Iran but no framework for active ageing strategies tailored to the social and cultural context has been designed for the elderly and health care providers.

The findings of this study showed that "personal active ageing strategies" performed by Iranian elders beyond threats and opportunity. In fact, each individual's efforts, knowledge, personal experiences and the conditions of life determine his/her state of active ageing. This highlights the need to identify older adults' individual capacities.

It is also important to remember that an active ageing will not be achieved exclusively by individual action, physical environment may be as a strong predictor for active ageing among the Iranian elderly. Providing proper technologies and equipment may be a helpful strategy to promote the activity status and to reduce the probability of injury-related risks.

Considering seniors' capacities and life opportunities, introducing these opportunities and capacities to elders and educating them how to implement their life opportunities could be an effective strategy for active ageing. Policymakers should consider, design, and implement programs to empower older to follow prevention strategies, exercise internal self-control, cope with threats, and optimize aging opportunities. This study was performed on the elderly living in Isfahan and it is recommended to conduct separate studies on the elderly from other cities to enable comparison. Although lack of generalizability is one of the weaknesses of qualitative studies, accurate description of the participants and maximum variation sampling in this study enable judgment by the readers.

\section{Acknowledgments}

We thank all individuals who participated in this research.

\section{Conflict of interest and funding}

The authors declare that there are no conflicts of interest. This research was supported partially by Isfahan university of Medical Science. 


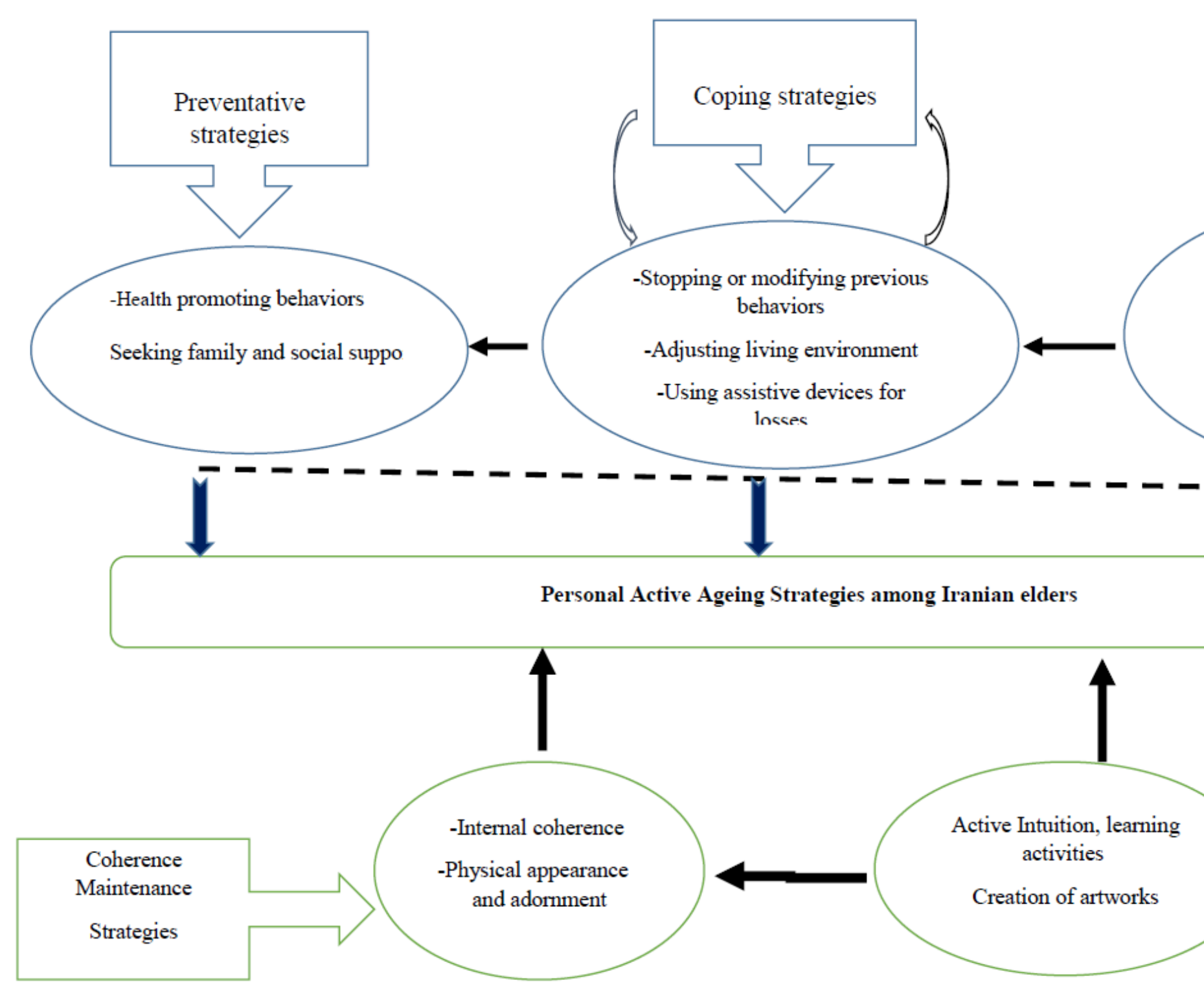

\section{References:}

Afshar, P. F., Asgari, P., Shiri, M., \& Bahramnezhad, F. (2016). A review of the Iran's elderly status according to the census records. Galen Medical Journal, 5(1), 1-6.

Ahmadi, F., Khodayarifard, M., Zandi, S., Khorrami-Markani, A., Ghobari-Bonab, B., Sabzevari, M., \& Ahmadi, N. (2018). Religion, culture and illness: a sociological study on religious coping in Iran. Mental Health, Religion \& Culture, 21(7), 721-736.

Ajam Zibad, H., Mohammadi Shahboulaghi, F., Foroughan, M., Rafiey, H., \& Rassouli, M. (2016). What is the meaning of spiritual health among older adults? A concept analysis. Educational Gerontology, 42(12), 795-808.

Alizadeh, T., Keshavarz, Z., Mirghafourvand, M., \& Zayeri, F. (2018). Investigation of health promoting lifestyle and social support and their correlation among Iranian women with multiple sclerosis. Int J Women's Health Reprod Sci, 6(2), 167-173. 
Anmarkrud, Ø., Andresen, A., \& Bråten, I. (2019). Cognitive load and working memory in multimedia learning: Conceptual and measurement issues. Educational Psychologist, 54(2), 61-83.

Asrani, S. K., Kouznetsova, M., Ogola, G., Taylor, T., Masica, A., Pope, B., . . Kanwal, F. (2018). Increasing health care burden of chronic liver disease compared with other chronic diseases, 2004-2013. Gastroenterology, 155(3), 719-729. e714.

Bagheri-Nesami, M., Rafii, F., \& H. Oskouie, S. F. (2010). Coping strategies of Iranian elderly women: A qualitative study. Educational Gerontology, 36(7), 573-591.

Bastani, F., \& Beigi Boroujeni, P. (2019). The Association between the Perception of Aging and Functional Independence in the Elderly Patients with Type II Diabetes Mellitus. Iran Journal of Nursing, 32(117), 7-21.

Blevins, C., \& Troutman, M. F. (2011). Successful aging theory and the patient with chronic renal disease: Application in the clinical setting. Nephrology Nursing Journal, 38(3), 255.

Bonsu, N. O., Dhubháin, Á. N., \& O'Connor, D. (2019). Understanding forest resource conflicts in Ireland: A case study approach. Land Use Policy, 80, 287-297.

Boucher, R.-A., \& Dahlke, S. (2019). Applying Selective Optimization and Compensation Model to Mobility Adaptations of Older Adults: An Integrative Review and Implications for Nursing Care. International Journal of Nursing Student Scholarship, 6.

Boudiny, K., \& Mortelmans, D. (2011). A critical perspective: towards a broader understanding of'active ageing'. E-journal of applied psychology, 7(1), 8-14.

Brojeni, S. A., Ilali, E.-S., Taraghi, Z., \& Mousavinasab, N. (2019). Lifestyle and its related factors in elderly. Journal of Nursing and Midwifery Sciences, 6(1), 32.

Butler, R. N. (1963). The life review: An interpretation of reminiscence in the aged. Psychiatry, 26(1), 65-76.

Buys, L., \& Miller, E. (2006). The meaning of" active ageing" to older Australians: Exploring the relative importance of health, participation and security.

Chan, C.-M. A., \& Liang, J.-S. E. (2013). Active aging: Policy framework and applications to promote older adult participation in Hong Kong. Ageing International, 38(1), 28-42.

Chen, Y., Harris, S. K., Worthington Jr, E. L., \& VanderWeele, T. J. (2019). Religiously or spiritually-motivated forgiveness and subsequent health and well-being among young adults: An outcome-wide analysis. The journal of positive psychology, 14(5), 649-658.

Chung, S., \& Park, H. (2019). How young and older people differ in discriminatory behaviour towards older people? An explanation of the knowledge-attitude-behaviour continuum model. Ageing \& Society, 39(9), 1996-2017.

Costa, L. V., Veloso, A. I., Loizou, M., \& Arnab, S. (2018). Breaking barriers to gamebased learning for active ageing and healthy lifestyles A qualitative interview study with 
experts in the field. Paper presented at the 2018 IEEE 6th International Conference on Serious Games and Applications for Health (SeGAH).

Cox, C., \& Pardasani, M. (2017). Aging and human rights: a rights-based approach to social work with older adults. Journal of Human Rights and Social Work, 2(3), 98-106.

Cunti, A., \& Bellantonio, S. (2018). Education, physical activity, and healthy aging in Italy: Theoretical and operating dimensions Ageing, Physical Activity and Health (pp. 175-188): Routledge.

Davies, N. (2011). Promoting healthy ageing: the importance of lifestyle. Nursing Standard (through 2013), 25(19), 43.

Del Barrio, E., Marsillas, S., Buffel, T., Smetcoren, A.-S., \& Sancho, M. (2018). From Active Aging to Active Citizenship: The Role of (Age) Friendliness. Social Sciences, 7(8), 134.

del Pilar Díaz-López, M., López-Liria, R., Aguilar-Parra, J. M., \& Padilla-Góngora, D. (2016). Keys to active ageing: new communication technologies and lifelong learning. SpringerPlus, 5(1), 768.

DeLisi, M. (2014). Low self-control is a brain-based disorder. The nurture versus biosocial debate in criminology: On the origins of criminal behavior and criminality, 172-184.

Desjardins, R., Olsen, D. S., \& Midtsundstad, T. (2019). Active ageing and older learnersSkills, employability and continued learning. European Journal of Education, 54(1), 1-4.

Dickerson, D., Baldwin, J. A., Belcourt, A., Belone, L., Gittelsohn, J., Kaholokula, J. K. a., . . . Wallerstein, N. (2018). Encompassing cultural contexts within scientific research methodologies in the development of health promotion interventions. Prevention Science, 1-10.

Ding, H., Jiang, T., \& Riloff, E. (2018). Why is an event affective? classifying affective events based on human needs. Paper presented at the Workshops at the Thirty-Second AAAI Conference on Artificial Intelligence.

Eagle, D. E., Hybels, C. F., \& Proeschold-Bell, R. J. (2019). Perceived social support, received social support, and depression among clergy. Journal of Social and Personal Relationships, 36(7), 2055-2073.

Fancourt, D., Garnett, C., Spiro, N., West, R., \& Müllensiefen, D. (2019). How do artistic creative activities regulate our emotions? Validation of the Emotion Regulation Strategies for Artistic Creative Activities Scale (ERS-ACA). PloS one, 14(2), e0211362.

Farzanegan, M. R., \& Alaedini, P. (2016). Economic welfare and inequality in Iran: Springer.

Fernández-Ballesteros, R., Molina, M. Á., Schettini, R., \& Del Rey, Á. L. (2012). Promoting active aging through university programs for older adults. GeroPsych.

Fernandez-Ballesteros, R., Olmos, R., Santacreu, M., Bustillos, A., \& Molina, M. A. (2017). The role of perceived discrimination on active aging. Archives of gerontology and geriatrics, $71,14-20$. 
Fernández-Ballesteros, R., Robine, J. M., Walker, A., \& Kalache, A. (2013). Active aging: a global goal. Current Gerontology and Geriatrics Research, 2013.

Ferreira, O. G. L., Maciel, S. C., Silva, A. O., Santos, W. S. d., \& Moreira, M. A. S. P. (2010). Active aging from the perspective of aged individuals who are functionally independent. Revista da Escola de Enfermagem da USP, 44(4), 1065-1069.

Finley, A. J., \& Schmeichel, B. J. (2019). Aftereffects of self-control on positive emotional reactivity. Personality and Social Psychology Bulletin, 45(7), 1011-1027.

Flood, M., \& Phillips, K. D. (2007). Creativity in older adults: A plethora of possibilities. Issues in Mental Health Nursing, 28(4), 389-411.

Formosa, M. (2019a). Active ageing through lifelong learning: The University of the Third Age The University of the Third Age and Active Ageing (pp. 3-18): Springer.

Formosa, M. (2019b). Third Age Learning for Active Ageing in Malta: Successes and Limitations The University of the Third Age and Active Ageing (pp. 81-93): Springer.

Foster, L. (2018). Active ageing, pensions and retirement in the UK. Journal of Population Ageing, 11(2), 117-132.

George, W., \& Dixon, A. (2018). Understanding the presence of Gerotranscendence among older adults. Adultspan Journal, 17(1), 27-40.

Gulia, K. K., \& Kumar, V. M. (2018). Sleep disorders in the elderly: a growing challenge. Psychogeriatrics, 18(3), 155-165.

Hassani, P., Izadi-Avanji, F.-S., Rakhshan, M., \& Majd, H. A. (2017). A phenomenological study on resilience of the elderly suffering from chronic disease: a qualitative study. Psychology research and behavior management, 10, 59.

Heravi-Karimooi, M., Anoosheh, M., Foroughan, M., Sheykhi, M. T., \& Hajizadeh, E. (2010). Understanding loneliness in the lived experiences of Iranian elders. Scandinavian Journal of Caring Sciences, 24(2), 274-280.

Hirai, H., Kondo, K., \& Kawachi, I. (2012). Social determinants of active aging: Differences in mortality and the loss of healthy life between different income levels among older Japanese in the AGES Cohort Study. Current Gerontology and Geriatrics Research, 2012.

Hsu, H.-C., \& Chang, W.-C. (2015). Social connections and happiness among the elder population of Taiwan. Aging \& mental health, 19(12), 1131-1137.

Illario, M., Vollenbroek-Hutten, M. M., Molloy, D. W., Menditto, E., Iaccarino, G., \& Eklund, P. (2016). Active and healthy ageing and independent living 2016. Journal of aging research, 2016. 
Jumadi, N., Noor, N. A. M., Bujang, A. A., Maimun, N. H. A., Ismail, W. I. F. W., Yusoff, N. S. M., \& Rahman, M. S. A. (2019). ACTIVE AGEING AND HOUSING ENVIRONMENT CONCEPT AMONG ELDERLY MUSLIMS. PLANNING MALAYSIA JOURNAL, 17(9).

Kahana, E., \& Kahana, B. (2001). Successful aging among people with HIV/AIDS. Journal of Clinical Epidemiology, 54(12), S53-S56.

Katz, S. (2013). Active and successful aging. Lifestyle as a gerontological idea. Recherches sociologiques et anthropologiques, 44(44-1), 33-49.

Kim, S., \& Lee, Y. (2018). Why do women want to be beautiful? A qualitative study proposing a new "human beauty values" concept. PloS one, 13(8), e0201347.

Kowal, P., \& Dowd, J. E. (2001). Definition of an older person. Proposed working definition of an older person in Africa for the MDS Project. World Health Organization, Geneva, doi, 10(2.1), 5188.9286.

Lachman, M. E. (2006). Perceived control over aging-related declines: Adaptive beliefs and behaviors. Current Directions in Psychological Science, 15(6), 282-286.

Lai, O.-K. (2008). The enigma of Japanese ageing-in-place practice in the information age: does digital gadget help the (good) practice for inter-generation care? Ageing International, 32(3), 236-255.

Landi, F., Calvani, R., Picca, A., Tosato, M., Martone, A. M., D’Angelo, E., . . Marzetti, E. (2018). Impact of habitual physical activity and type of exercise on physical performance across ages in community-living people. PloS one, 13(1), e0191820.

Larsson, B., Hildingsson, I., Ternström, E., Rubertsson, C., \& Karlström, A. (2019). Women's experience of midwife-led counselling and its influence on childbirth fear: a qualitative study. Women and Birth, 32(1), e88-e94.

Lee, C.-S., Ryu, E.-K., \& Choi, Y.-J. (2019). The Effect of Quality of Life and Hope on the Suicide Ideation of the Elderly: The Moderated Mediation Effect of Participation in Lifelong Education. Medico-Legal Update, 19(1), 310-316.

Lee, E. (2018). Who are those happy elderly people?

Lentz, T. A., \& Brown, C. (2019). Mindfulness and health behaviors in college students: The moderating role of sleep. Journal of American College Health, 67(6), 505-514.

Liotta, G., Canhao, H., Cenko, F., Cutini, R., Vellone, E., Illario, M., . . . Palombi, L. (2018). Active ageing in Europe: adding healthy life to years. Frontiers in medicine, 5, 123.

Liu, J., Rozelle, S., Xu, Q., Yu, N., \& Zhou, T. (2019). Social Engagement and Elderly Health in China: Evidence from the China Health and Retirement Longitudinal Survey (CHARLS). International journal of environmental research and public health, 16(2), 278.

Lobos, G., Lapo, M. d. C., \& Schnettler, B. (2016). In the choice between health and money, health comes first: an analysis of happiness among rural Chilean elderly. Cadernos de saude publica, 32, e00032215. 
Lucchetti, G., Vitorino, L. M., Nasri, F., \& Lucchetti, A. L. G. (2019). Impact of Religion and Spirituality in Older Persons Spirituality, Religiousness and Health (pp. 115-130): Springer.

Luchesi, B. M., de Oliveira, N. A., de Morais, D., de Paula Pessoa, R. M., Pavarini, S. C. I., \& Chagas, M. H. N. (2018). Factors associated with happiness in the elderly persons living in the community. Archives of gerontology and geriatrics, 74, 83-87.

Lune, H., \& Berg, B. L. (2016). Qualitative research methods for the social sciences: Pearson Higher Ed.

Luth, E. A. (2016). Future time perspective and end-of-life planning in older adults. Research on aging, 38(2), 178-201.

Marcum, C. S. (2013). Age differences in daily social activities. Research on aging, 35(5), 612-640.

Mašanović, B., Popović, S., Bjelica, D., Vukotic, M., \& Zoric, G. (2018). The effects of physical activity on depressive symptoms among elderly people: a systematic review. Paper presented at the Proceedings World Congress of Performance Analysis of Sport XII.

Mehri, N., Messkoub, M., \& Kunkel, S. (2019). Trends, determinants and the implications of population aging in Iran.

Mendoza-Ruvalcaba, N. M., \& Fernández-Ballesteros, R. (2016). Effectiveness of the Vital Aging program to promote active aging in Mexican older adults. Clinical interventions in aging, 11, 1631.

Miao, J., Wu, X., \& Sun, X. (2019). Neighborhood, social cohesion, and the Elderly's depression in Shanghai. Social Science \& Medicine, 229, 134-143.

Mihas, P. (2019). Qualitative data analysis Oxford Research Encyclopedia of Education.

Mitzner, T. L., Boron, J. B., Fausset, C. B., Adams, A. E., Charness, N., Czaja, S. J., . . . Sharit, J. (2010). Older adults talk technology: Technology usage and attitudes. Computers in Human Behavior, 26(6), 1710-1721.

Mohammadi, E., Allahyari, T., Darvishpoor Kakhaki, A., \& Saraei, H. (2018). Determining Psychometric Properties of Iranian Active Aging Measurement Instrument. Iranian Journal of Ageing, 12(4), 414-429.

Monfared, A., Soodmand, M., Ghasemzadeh, G., Mirzaee, S., Mohammadi, M., \& Amoozadeh Licha, N. (2019). Study of Lifestyle, Sleep Quality, and Related Factors in Hemodialysis Patients. Journal of Holistic Nursing And Midwifery, 29(3), 37-45.

Morelhão, P. K., Pinto, R. Z., Gobbi, C., Tufik, S., \& Andersen, M. L. (2018). Can sleep problems have a negative impact on falls in older people? Journal of clinical sleep medicine, 14(10), 1821-1822. 
Moulaert, T., \& Paris, M. (2013). Social policy on ageing: The case of active ageing as a theatrical metaphor. Int'l J. Soc. Sci. Stud., 1, 113.

Mousavi, G., Khorasani-Zavareh, D., Ardalan, A., Khankeh, H., Ostadtaghizadeh, A., Kamali, M., \& Raissi, G. (2019). Continuous post-disaster physical rehabilitation: a qualitative study on barriers and opportunities in Iran. Journal of Injury and Violence Research, 11(1), 35.

Murray, C. J., Ferguson, B. D., Ahmad, O. B., Lopez, A. D., Salomon, J. A., Mathers, C. D., \& Organization, W. H. (2001). Methods for life expectancy and healthy life expectancy uncertainty analysis/Joshua A. Salomon...[et al.].

Naik, B. N., Reddy, M. M., \& Kanungo, S. (2019). Elderly and health: Role of spirituality in Indian context. Yoga Mimamsa, 51(1), 38.

Nantsupawat, W., Kamnuansilapa, P., Sritanyarat, W., \& Wongthanawasu, S. (2010). Family relationships, roles and the meaning of active aging among rural Northeastern Thai elders. Pacific Rim International Journal of Nursing Research, 14(2), 137-148.

Narushima, M., Liu, J., \& Diestelkamp, N. (2018). Lifelong learning in active ageing discourse: its conserving effect on wellbeing, health and vulnerability. Ageing \& Society, 38(4), 651-675.

Organization, W. H. (2002). Active ageing: A policy framework: Geneva: World Health Organization.

Ouwehand, C., de Ridder, D. T., \& Bensing, J. M. (2007). A review of successful aging models: Proposing proactive coping as an important additional strategy. Clinical psychology review, 27(8), 873-884.

Pandey, J. (2019). Deductive approach to content analysis Qualitative Techniques for Workplace Data Analysis (pp. 145-169): IGI Global.

Pashaki, N. J., Mohammadi, F., Jafaraghaee, F., \& Mehrdad, N. (2015). Factors influencing the successful aging of Iranian old adult women. Iranian Red Crescent Medical Journal, 17(7).

Pavelek, L. (2012). How can volunteering improve the individual and social life of the elderly. Social and Natural Sciences Journal, 6.

Pichler, N. A., Scortegagna, H. d. M., Dametto, J., Frizon, D. M. S., Zancanaro, M. P., \& Oliveira, T. C. d. (2019). Reflections on the perception of the elderly regarding happiness and money. Revista Brasileira de Geriatria e Gerontologia, 22(2).

Pierpaoli, C. M., \& Parmelee, P. A. (2017). Feelings of Usefulness to Others Predict Active Coping With Osteoarthritis Knee Pain. Journal of aging and health, 29(5), 826-841.

Piotrowicz, K., Romanik, W., Skalska, A., Gryglewska, B., Szczerbińska, K., Derejczyk, J., . . Gąsowski, J. (2019). The comparison of the 1972 Hodkinson's Abbreviated Mental Test Score (AMTS) and its variants in screening for cognitive impairment. Aging clinical and experimental research, 31(4), 561-566. 
Principi, A., Santini, S., Socci, M., Smeaton, D., Cahill, K. E., Vegeris, S., \& Barnes, H. (2018). Retirement plans and active ageing: Perspectives in three countries. Ageing \& Society, 38(1), 56-82.

Rantanen, T., Saajanaho, M., Karavirta, L., Siltanen, S., Rantakokko, M., Viljanen, A., ... Lisko, I. (2018). Active aging-resilience and external support as modifiers of the disablement outcome: AGNES cohort study protocol. BMC Public Health, 18(1), 565.

Rasmussen, K. R., Stackhouse, M., Boon, S. D., Comstock, K., \& Ross, R. (2019). Metaanalytic connections between forgiveness and health: the moderating effects of forgivenessrelated distinctions. Psychology \& Health, 34(5), 515-534.

Robertson, G. (2013). The contribution of volunteering and a wider asset based approach to active ageing and intergenerational solidarity in Europe. Working with older people, 17(1), 718.

Schilling, O. K., Wahl, H.-W., Boerner, K., Reinhardt, J. P., Brennan-Ing, M., \& Horowitz, A. (2012). Change in psychological control in visually impaired older adults over 2 years: Role of functional ability and depressed mood. Journals of Gerontology Series B: Psychological Sciences and Social Sciences, 68(5), 750-761.

Seib, C., McCarthy, A., McGuire, A., Porter-Steele, J., Balaam, S., \& Anderson, D. (2019). Promoting healthy lifestyle changes to improve health-related quality of life in women after cancer: results from the Australian women's wellness after cancer program (WWACP). Maturitas, 124, 149.

Shackman, A. J., Tromp, D. P., Stockbridge, M. D., Kaplan, C. M., Tillman, R. M., \& Fox, A. S. (2016). Dispositional negativity: An integrative psychological and neurobiological perspective. Psychological bulletin, 142(12), 1275.

Shi, L., Chen, S.-J., Ma, M.-Y., Bao, Y.-P., Han, Y., Wang, Y.-M., . . Lu, L. (2018). Sleep disturbances increase the risk of dementia: a systematic review and meta-analysis. Sleep medicine reviews, 40, 4-16.

Sottimano, I., Guidetti, G., Viotti, S., \& Converso, D. (2019). The Interplay between Job Control, SOC Strategies, and Age in Sustaining Work Ability in a Sample of Administrative Employees. Sustainability, 11(5), 1463.

Speziale, H. S., Streubert, H. J., \& Carpenter, D. R. (2011). Qualitative research in nursing: Advancing the humanistic imperative: Lippincott Williams \& Wilkins.

St-Onge, M.-P., Crawford, A., \& Aggarwal, B. (2018). Plant-based diets: Reducing cardiovascular risk by improving sleep quality? Current sleep medicine reports, 4(1), 74-78.

Tastan, S., Ayhan, H., Kose, G., Iyigun, E., \& Gokcul, S. (2019). Analysis of the relationship between the autonomy of Turkish elderly people and their happiness and anxietydepression status: a cross-sectional study. International psychogeriatrics, 1-2. 
Thanakwang, K., Isaramalai, S.-a., \& Hattakit, U. (2014). Thai cultural understandings of active ageing from the perspectives of older adults: a qualitative study. Pacific Rim International Journal of Nursing Research, 18(2), 152-165.

The University of the Third Age (U3A) in Iran: a Model for Successful Ageing. (2017, October, 23). Retrieved from http:// http://en.zaums.ac.ir/news-Events:17233.html

UdO, D. S. (2016). ACTIVE AGEING: A CONCEPT ANALYSIS. Caribbean Journal of Nursing, 3(1), 59-79.

van Dyk, S., \& Turner, M. (2010). Active, productive and healthy aging in Germany and the United States. AARP International [Online].[cited 2011].

Victor, C. (2004). The social context of ageing: A textbook of gerontology: Routledge.

Wakasai, A., Matsumoto, K., \& Kakehashi, C. (2006). A Study on Successful Aging of Middle-and Advanced-Aged People-with Major Focus on the Current Status of Women in their Mature Stage Living in Three Districts in Japan. Kawasaki J Med Welf, 12(1), 45-53.

Walker, A. (2002). A strategy for active ageing. International social security review, 55(1), 121-139.

Walker, A. (2019). Conclusion: Realising Active Ageing The Future of Ageing in Europe (pp. 309-328): Springer.

Walker, A., \& Zaidi, A. (2019). Strategies of active ageing in Europe The Future of Ageing in Europe (pp. 29-52): Springer.

Walkner, A. J., \& Rueter, M. A. (2014). Adoption status and family relationships during the transition to young adulthood. Journal of Family Psychology, 28(6), 877.

Winzer, L., \& Gray, R. S. (2019). The role of Buddhist practices in happiness and health in Thailand: A Structural Equation Model. Journal of Happiness Studies, 20(2), 411-425.

Wu, Y. T., Clare, L., Jones, I. R., Martyr, A., Nelis, S. M., Quinn, C., . . Matthews, F. E. (2018). Inequalities in living well with dementia-The impact of deprivation on well-being, quality of life and life satisfaction: Results from the improving the experience of dementia and enhancing active life study. International journal of geriatric psychiatry, 33(12), 1736-1742.

Zaidi, A., \& Howse, K. (2017). The policy discourse of active ageing: Some reflections. Journal of Population Ageing, 10(1), 1-10.

Zhang, J. (2012). Regional Context, Market Transition, and Successful Aging: Results from Transitional China.

Zhao, C., Noble, J. M., Marder, K., Hartman, J. S., Gu, Y., \& Scarmeas, N. (2018). Dietary Patterns, Physical Activity, Sleep, and Risk for Dementia and Cognitive Decline. Current nutrition reports, 7(4), 335-345. 